\title{
Primary care physicians' educational needs and learning preferences in end of life care: A focus group study in the UK
}

\author{
Lucy Ellen Selman ${ }^{*}$, Lisa Jane Brighton², Vicky Robinson², Rob George ${ }^{2,3}$, Shaheen A. Khan ${ }^{4}$, Rachel Burman ${ }^{5}$
} and Jonathan Koffman ${ }^{2}$

\begin{abstract}
Background: Primary care physicians (General Practitioners (GPs)) play a pivotal role in providing end of life care (EoLC). However, many lack confidence in this area, and the quality of EoLC by GPs can be problematic. Evidence regarding educational needs, learning preferences and the acceptability of evaluation methods is needed to inform the development and testing of EoLC education. This study therefore aimed to explore GPs' EoLC educational needs and preferences for learning and evaluation.

Methods: A qualitative focus group study was conducted with qualified GPs and GP trainees in the UK. Audio recordings were transcribed and analysed thematically. Expert review of the coding frame and dual coding of transcripts maximised rigour.

Results: Twenty-eight GPs (10 fully qualified, 18 trainees) participated in five focus groups. Four major themes emerged: (1) why education is needed, (2) perceived educational needs, (3) learning preferences, and (4) evaluation preferences. EoLC was perceived as emotionally and clinically challenging. Educational needs included: identifying patients for palliative care; responsibilities and teamwork; out-of-hours care; having difficult conversations; symptom management; non-malignant conditions; and paediatric palliative care. Participants preferred learning through experience, working alongside specialist palliative care staff, and discussion of real cases, to didactic methods and e-learning. $360^{\circ}$ appraisals and behavioural assessment using videoing or simulated interactions were considered problematic. Self-assessment questionnaires and patient and family outcome measures were acceptable, if used and interpreted correctly.
\end{abstract}

Conclusions: GPs require education and support in EoLC, particularly the management of complex clinical care and counselling. GPs value mentoring, peer-support, and experiential learning alongside EoLC specialists over formal training.

Keywords: General Practice, Primary Health Care, Education, End of Life Care, Palliative Care, Qualitative Research

\section{Background}

General Practitioners (GPs) and other community healthcare providers are vital to the delivery of end of life care (EoLC) internationally, assuming overall responsibility for direct patient care, providing generalist palliative care, ensuring co-ordination and communication with colleagues and social care providers, and preventing unnecessary hospital admissions [1-4]. In

\footnotetext{
* Correspondence: lucy.selman@bristol.ac.uk

'University of Bristol, School of Social and Community Medicine, University of Bristol, 39 Whatley Road, Bristol BS8 2PS, UK

Full list of author information is available at the end of the article
}

England, where the current study was conducted, GPs' responsibilities now include commissioning of services in local communities. Working in Clinical Commissioning Groups (CCGs) with other practices, GPs are key players in making the wider systemic changes required to improve EoLC [5] and help shift care from hospitals to the community, in line with patient wishes $[6,7]$.

However, there is evidence that GPs encounter challenges in providing EoLC and that the quality of EoLC by GPs can be problematic [8-11]. A recent survey of bereaved relatives of 596 people who died of cancer in London, UK, found that GPs received significantly less 
favourable ratings than district, community or private nurses providing homecare and specialist palliative care providers, with $28.2 \%$ of GP care rated very poor, poor, or fair [12]. However, EoLC is a relatively small component of a GP's workload and staying abreast of developments in policy and practice presents challenges [11, 13-15]. Furthermore, training in EoLC for general practice has its limitations [15-17]. A systematic review of palliative care delivery by GPs found that many GPs feel ill-prepared and lack confidence in EoLC, despite being considered vital players in its delivery, and despite valuing this part of their work [9]. GPs reported feeling particularly challenged in managing patients' and family carers' psychological needs, pain and other symptoms. Policy guidance is right to recognise the urgent need for evidence-based education in EoLC for GPs [5, 18].

The literature describes several GP training interventions. Yet their evidence base is often unclear and few have been rigorously evaluated [19]. Where training is based on evidence, it usually concerns the training and education GPs require [20], rather than their learning preferences $[17,21]$. In the UK, a pilot study of training and support materials (leaflets, postcards and posters) for GPs was conducted in 2011 by the Dying Matters Coalition [22]. However, of the 59 participants, only 25 attended a training workshop, and it is unclear how the content and format of the training were developed. While the Gold Standards Framework (GSF) team offers GP training on the use of the GSF as a set of guidelines, mechanisms and assessment tools, up to now evaluation has focused on categorical questions about the implementation of organisational and clinical processes, and self-rated assessments of quality associated with palliative care provision, rather than staff, patient or family outcomes [23, 24]. No rigorous evaluations exist of GP EoLC training in the UK [18]. Outside the UK, evaluations of GP EoLC education have had mixed results, with a recent controlled trial of a palliative care training programme for GPs finding no significant effect on communication skills or patient outcomes [25, 26].

To inform the development and evaluation of UK EoLC education for GPs, we aimed to explore their educational needs, preferred learning methods, and acceptable methods of evaluation.

\section{Methods}

\section{Study design}

Face-to-face semi-structured focus groups were conducted with trainee and qualified GPs.

\section{Setting}

Participants either worked at a CCG or were trainees completing their specialist training (ST1, ST2 and ST3 years; ST1 is the first year and ST3 the last) in a large
UK city. Focus groups were held at convenient times and locations around existing events so as not to interfere with work or study schedules: one took place at a conference centre where an event on cancer care in primary care was being held, one at the research department in line with the schedules of interested participants, and three at a residential conference centre where an away day for trainee GPs was scheduled.

\section{Sampling and recruitment}

Inclusion criteria were: practicing as a GP or training to be a GP. Practicing GPs were recruited in two ways: advertisement in the electronic bulletin to the CCG mailing list, and in-person by the researchers at the event on cancer in primary care. Trainees were recruited in-person by the researchers during the away days. Maximum variation sampling aimed to capture diversity of age, years of experience, gender, and ethnicity. Data collection continued until data saturation was reached [27].

\section{Data collection}

Focus groups were facilitated by experienced researchers with academic backgrounds in palliative care and health psychology and an interest in the education of healthcare professions (LS or LB), following best practice [28]. Another researcher or research administrator (LB or LK) attended each focus group to take field notes on environmental factors and non-verbal behaviours during and immediately after each group. The researchers and administrator were not known by participants and introduced themselves as academic researchers unconnected to the CCG or their training programme. Guidelines including maintaining confidentiality, allowing all participants to speak and there being no right or wrong answers, were explained at the beginning of each focus group. The research was part of a wider study generating data to inform future training in palliative and EoLC and its evaluation. We defined EoLC broadly as care of patients with incurable, progressive and life-limiting disease, and palliative care as an holistic approach to EoLC in line with the World Health Organization definition [29]. The topic guide (Table 1) was based on gaps in the existing literature, and revised with input from the project team and lay advisory group (one patient with advanced disease and four family caregivers). To prompt discussion, during the focus groups participants were given handouts listing the topics covered in a current two-day training on palliative and EoLC held in a local hospital [30] (Table 2), and asked to reflect on which of these would be relevant or not for GPs. The focus groups were recorded, transcribed verbatim and anonymised. Participants also completed a brief demographics form. 
Table 1 Topic guide

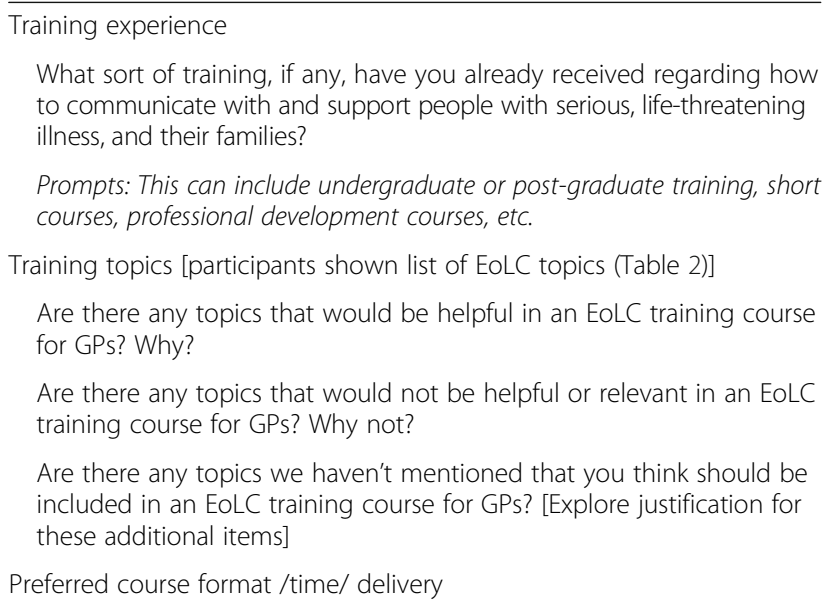

How long should a course be? Prompts: Would you prefer shorter sessions over multiple days, or fewer longer sessions? Two days? One day?

When should it be held? Prompt: Are particular times of day best?

Who should attend? Prompt: Would you prefer a course attended by many different healthcare professionals or GPs only? What benefits are there to multi-professional learning? What drawbacks?

Who should teach the course? Prompt: hospital/community palliative care staff? Other generalist providers e.g. GPs?

How should it be taught? Prompt: in-person versus online, as lectures versus interactive skills training. What about a mixture of in-person and online resources?

Where should it be held? Prompt: at a local hospital? Local hospice? Non-medical location?

Mentoring / ongoing supervision techniques

Do you think that ongoing mentoring or supervision would be useful or not useful alongside an end of life care training course?

Prompts: If yes, what do you think would be the best way to provide this? What are your views of mentoring by an expert by experience, i.e. patient/family member? If you don't think mentoring/supervision would be useful, why not?

Testing training effectiveness

How would you feel about us assessing the effectiveness of the training course by...

videoing or audio-recording your encounters with real or actor patients or families?

using patient or family satisfaction measures?

using $360^{\circ}$ appraisals from colleagues, managers, patients and family members?

using process outcomes, for example referral to palliative care or place of death?

Prompts: Are any of these methods particularly preferable or not preferable? Why?

\section{Analysis}

Transcripts and associated field notes were analysed within a minimal realist paradigm [31] using thematic analysis [32] to describe the data and explore emerging patterns. This process comprised five stages:
Table 2 Topic list

Understanding patients'/families' priorities in EoLC

Understanding your role in EOLC

Using the Amber Care Bundle [34, 35]

Helping patients achieve their preferred place of care

Fast Track discharges [37]

Understanding and managing common symptoms in dying patients

Understanding spiritual and cultural aspects of dying

Having difficult conversations with patients and families

Understanding advance care planning and using Coordinate My Care [37]

Understanding grief and providing support for family experiencing bereavement

Familiarisation with the data and inductive coding of five transcripts to generate a draft coding frame (LB); (2) Refinement of the coding frame with input from academic and clinical members of the project team; (3) Application of the final coding frame to all data (LB); (4) Independent dual coding of a sample of two transcripts by academic and clinical team members to assess inter-rater reliability [33] and refine the coding frame (JK, VR); (5) Review of all coding and generation of a narrative summary, paying attention to deviant cases within each theme and differences between trainees and qualified GPs [34] (LS). Analysis was managed in QSR NVivo 10 [35].

\section{Results}

Data saturation was reached after five focus groups, totalling 28 participants. Mean length of the groups was 55 mins (range 35-82 mins). Participants comprised 18 trainees (8 ST1s, 3 ST2s, 7 ST3s) and 10 GPs (median years in practice 109 , range $3-45$ ). The majority were women (79\%), with a median age of 32 (range 27-63) (Table 3). Four themes related to the study aims: why education is needed, perceived educational needs, and preferences for learning and evaluation.

\section{Why education is needed}

All participants recognised the importance and relevance of EoLC: 'Generalists should be specialists in end of life care because we are the coordinators at the end.' (GP04). All except one participant believed there to be a need for more or better education in EoLC. The reasons given fell into four sub-themes: attrition of skills and the difficulty of keeping up to date; inadequate exposure to care of the dying during training and in clinical practice; a lack of confidence, and the complexity of EoLC. One GP felt that training was not the answer to improving EoLC: 'The training model is one that I would question, because I don't think we can train people to do these things. We can certainly help, help people develop. It's like training 
Table 3 Demographic characteristics

\begin{tabular}{|c|c|c|c|c|c|}
\hline ID & Job Title & $\begin{array}{l}\text { Years in } \\
\text { practice/ } \\
\text { training }\end{array}$ & Gender & Age Group & Ethnicity \\
\hline$\overline{\mathrm{GP} 01}$ & GP & 15 & $F$ & $40-49$ & White British \\
\hline GP02 & GP & 5 & M & $30-39$ & White British \\
\hline GP03 & GP & 45 & M & $60-69$ & White British \\
\hline GP04 & GP & 20 & $\mathrm{~F}$ & $40-49$ & Sri Lankan \\
\hline GP05 & GP & 4 & M & $30-39$ & $\begin{array}{l}\text { White and } \\
\text { Black African }\end{array}$ \\
\hline GP06 & GP & 6 & $\mathrm{~F}$ & [not disclosed] & Pakistani \\
\hline GP07 & GP & 3 & $\mathrm{~F}$ & $30-39$ & Black African \\
\hline GP08 & GP & 12 & $\mathrm{~F}$ & $40-49$ & White British \\
\hline GP09 & GP & 35 & M & $60-69$ & White British \\
\hline GP10 & GP & 3 & $\mathrm{~F}$ & $40-49$ & Black African \\
\hline GP11 & GP Trainee & ST3 & $\mathrm{F}$ & $30-39$ & White British \\
\hline GP12 & GP Trainee & ST3 & $\mathrm{F}$ & $30-39$ & White British \\
\hline GP13 & GP Trainee & ST3 & $\mathrm{F}$ & $30-39$ & White British \\
\hline GP14 & GP Trainee & ST2 & $\mathrm{F}$ & $20-29$ & Indian \\
\hline GP15 & GP Trainee & ST1 & $\mathrm{F}$ & $20-29$ & White British \\
\hline GP16 & GP Trainee & ST2 & $\mathrm{F}$ & $20-29$ & Indian \\
\hline GP17 & GP Trainee & ST1 & M & $30-39$ & White British \\
\hline GP18 & GP Trainee & ST1 & $\mathrm{F}$ & $20-29$ & Pakistani \\
\hline GP19 & GP Trainee & ST1 & $\mathrm{F}$ & [not disclosed] & Pakistani \\
\hline GP20 & GP Trainee & ST1 & M & $20-29$ & White British \\
\hline GP21 & GP Trainee & ST2 & $\mathrm{F}$ & $30-39$ & $\begin{array}{l}\text { Other Mixed } \\
\text { /multiple }\end{array}$ \\
\hline GP22 & GP Trainee & ST3 & $\mathrm{F}$ & $30-39$ & White British \\
\hline GP23 & GP Trainee & ST3 & $\mathrm{F}$ & $30-39$ & White British \\
\hline GP24 & GP Trainee & ST1 & $\mathrm{F}$ & $20-29$ & [not disclosed] \\
\hline GP25 & GP Trainee & ST3 & $\mathrm{F}$ & $30-39$ & White British \\
\hline GP26 & GP Trainee & ST3 & $\mathrm{F}$ & $30-39$ & White British \\
\hline GP27 & GP Trainee & ST1 & $\mathrm{F}$ & $30-39$ & White British \\
\hline GP28 & GP Trainee & ST1 & $\mathrm{F}$ & $20-29$ & Indian \\
\hline
\end{tabular}

people in music or art or philosophy or something: it has to be inductive rather than structured... it's a matter of mentoring' (GP03).

\section{Attrition of skills and difficulty of keeping up-to-date}

Qualified GPs reported attrition in their symptom management skills, using drug charts and setting up syringe drivers: 'Unless you are doing it and getting experience prescribing and seeing patients you forget it instantly' (GP11). EoLC education received during GP specialisation, particularly regarding symptom management, was lost over time from lack of exposure and reliance on palliative care specialists or colleagues with a special interest in palliative care (e.g. Macmillan GP facilitators): 'You're trained to quite a high level. The difficulty is in real life... it's hard to maintain that, I would say particularly if you've got people that are very, very skilled like [Hospice] who take on a big burden of the palliative care... You end up doing less, so you become less skilled, particularly with things like medication use' (GP02).

\section{Inadequate exposure to care of the dying}

Both established GPs and current trainees reported inadequate, inconsistent education in and exposure to EoLC during undergraduate training and GP specialisation. Palliative care education was described as 'opportunistic', dependent on where and with whom you worked: 'If you happen to be rota'd onto a care of the elderly job, better for you, because you get to learn about it, but if you are not...' (GP14). This included ST3s soon to complete GP specialisation: 'I feel like I'd need a lot of support, so [EoLC]'s something that I need to try and get involved in before my training ends in three months' time. I don't feel that I'd be competent' (GP25). Amongst trainees, palliative care experience was more often gained in hospital placements than in the community (In the GP placement, a lot of the palliative patients go to the partners who know the families' (GP25)), but this was inadequate: 'A hospital is completely different... you have the support of nursing staff and... a palliative care team at the hospital... In general practice you don't have as much support' (GP21).

\section{Lack of confidence}

Due to limited palliative care education and experience, there was a widespread lack of confidence in EoLC amongst both qualified and trainee GPs. This was reported to lead to hospital admissions ('send them into a hospital and they can work out if it is reversible or not' (GP08)) and poor symptom control: 'I have bottled it more than once and under-treated somebody's pain because I am scared of giving out that much morphine.' (GP12). Confidence was lacking in particular topics: providing out-of-hours care, symptom management, identifying patients at the end of life, initiating palliative care, and some aspects of communication (e.g. initiating discussions about palliative care and communicating with families). Experience of managing EoLC in the community increased confidence: '[My GP trainer and I] had... a handover session with a patient and then, after that, I saw her on my own, with support from my trainer if I needed it, and that worked really well... it made me feel confident.' (GP21), and this practical clinical experience was seen as invaluable: 'Current registrars have a full curriculum statement [on EoLC] devised by locals GPs... But I think it is the practical skills that you need.' (GP04).

\section{The complexity of end of life care}

However, both experienced and trainee GPs reported EoLC to be complex and challenging in itself ('When 
you are just starting out, it is really scary' (GP10). EoLC could be personally difficult ('a big emotional burden... exhausting.' (GP02)), in part because 'there isn't an instruction manual and it depends on our humanity... and actually we all become helpless and powerless' (GP03). The real-life complexities of providing EoLC were challenging: communicating well with patients when time is short, resistance among patients to discussing death or dying, using local systems, or justifying a decision not to refer a patient to hospital or to stop their medication: 'When [the] specialist system doesn't understand what you are trying to do in primary care, you kind of start to fall apart already, because... someone along the line might challenge you and say, well, the microbiologist said you should do this and you haven't... So as much as you want to keep people at home, sometimes the specialist that you depend on... directs what you do.' (GP07). Although GPs who trained recently reported having more theoretical training in EoLC than those trained many years previously, this training often failed to acknowledge the complexities of real-life practice; for example, the difficulty of enabling a home death in line with a patient's wishes: 'I have so many examples of palliative care patients who had all the conversations... They are on that register they are always trying to get us to put people on, and then they still end up going and dying in hospital... You have spent however many hours, and you think, what really have I achieved here?' (GP05).

\section{Perceived educational needs}

Education needs arose in nine sub-themes: identification and referral for palliative care; local services and resources; local systems and frameworks; roles, responsibilities and teamwork; out-of-hours care; difficult conversations and counselling skills; symptoms and medication; caring for patients with non-malignant conditions; and paediatric palliative care (Table 4). Awareness of local and national initiatives such as the Amber Care Bundle [36, 37], the Gold Standards Framework [24, 38], Coordinate My Care [39] (a regional, electronic multi-access clinical care record) and procedures for Fast Track discharge [40] and out-of-hours care was patchy. GP trainees felt that communication skills were well covered in current training ('I don't think communication issues we need more of, I feel like we do those to death in GP [training], no pun intended there. [Laughter]' (GP11)), although some felt their skills could be better: 'I feel from all the role play and stuff we have done we are quite good at bumbling our way through it competently, but [we] could be more effective.' (GP12). While participants in general felt they had received enough communication skills training, initiating discussions of palliative care and provide emotional support to families nevertheless remained difficult.

\section{Learning preferences}

Both qualified and trainee GPs considered real-life experience of EoLC the gold standard: 'No more lectures. No. We need experience' (GP07). Participants valued highly placements at hospices and opportunities to shadow, discuss cases with and share care with specialist palliative care staff: 'What I am astounded by is actually the benefit and the close working when it goes well with our community nurses and with our specialist palliative care. It is brilliant. Getting out and find the consultant there on a joint visit, you learn so much.' (GP08). Faceto-face mentorship was suggested as a way of providing knowledgeable advice and a source of peer support that was particularly needed in EoLC ("[someone] to turn to, to sort of say, 'that was quite rough"' (GP02)).

As time is at a premium, participants felt training in EoLC needed to be easily integrated into clinical practice, existing meetings and training events. Multidisciplinary teachers and co-learners were favoured. Learning preferences reflected the high value placed on real-life experience: participants were particularly keen to learn from palliative care specialists or experienced GP mentors, and felt that reflection on real case studies in training was more effective for learning than didactic methods ('give a real life situation - what would you do, I think - rather than the theory, just the theory.' (GP23)). A role for services users was also suggested: 'discussions with actual relatives who have gone through it... seeing what they felt was good, what they felt was bad.' (GP24). E-learning elicited mixed views. Trainees were used to online learning and understood its value in terms of cost-effectiveness and flexibility, but several reported that they found online learning difficult to absorb and retain: 'You feel like a real expert for the first six weeks after you do it and then you forget it.' (GP11). Done well, role plays could be effective and memorable; however, trainees seemed saturated with the technique by their third year: 'There is only so much you can get out of pretending to tell your friend they are dying and having somebody observe you do it. I think I stopped learning from that about a year ago.' (GP12).

\section{Evaluation preferences}

Participants questioned the accuracy of $360^{\circ}$ appraisals in assessing quality of care: 'You pick the people... and they're probably people that you've had more interaction with'. (GP25). Participants felt that behavioural assessment using videoing was not acceptable unless it was required for a specific qualification. Several participants were averse to any form of behavioural evaluation: 'I personally avoid anything that's like a role-play where you're assessed. So, if there's like a simulation day, where I know you're going to be watched and assessed, I won't apply for it.' (GP24). Trainees also questioned the 
Table 4 GPs' perceived training needs

\begin{tabular}{|c|c|}
\hline Training need & Exemplifying quotation \\
\hline $\begin{array}{l}\text { Identifying and referring patients } \\
\text { for palliative care }\end{array}$ & $\begin{array}{l}\text { 'dentifying which patients need to be highlighted and prioritising those patients... I don't think we really do } \\
\text { that very well. I think they slip through the net quite easily.' (GP19) } \\
\text { 'Whether everyone needs to be referred to palliative care, or if there are people that we can manage in the } \\
\text { community without input, if we feel comfortable enough - I wouldn't know that decision. I would always refer, } \\
\text { because... I'm not comfortable with any of the medications.' (GP30) }\end{array}$ \\
\hline Local services and resources & $\begin{array}{l}\text { "Practical things - what do you actually do, who do you actually phone up, who's involved in that team... there } \\
\text { must be... all kinds of services going on that we just don't know about... that would be useful, to see 'these are } \\
\text { all the people, these are all the resources you potentially use and this is how you get hold of them." (GP02) }\end{array}$ \\
\hline Local systems and frameworks & $\begin{array}{l}\text { 'How does this system work in my locality? How do I contact this person? What advice, specifically, do I give? } \\
\text { What are the guidelines in my area? Where do I access them? That kind of thing.' (GP29) } \\
\text { "In my practice, some people don't know about hospital at home. So I've sent an email round saying, do you } \\
\text { know you can do this? It is really interesting. You will have five GPs and only one will know about hospital at } \\
\text { home or only one will know about 'Talk Kings' where you can get } 24 \text { h access to a consultant. And it is like it is } \\
\text { really bitty how we get our information." (GP09) }\end{array}$ \\
\hline Roles, responsibilities and team work & $\begin{array}{l}\text { 'You've got your role in their care, but knowing what you can legitimately expect of other team members, and } \\
\text { what it's not bad to ask them to do, or what they may offer in terms of support and things, I think that's quite } \\
\text { important, because I don't feel like I've got a good grasp of exactly what everyone could do in that team.' (GP19) }\end{array}$ \\
\hline Out-of-hours care & $\begin{array}{l}\text { 'I have had some phone calls about palliative patients in out of hours that [are]... more challenging because } \\
\text { you really just don't have any, well, very little background.' (GP25) }\end{array}$ \\
\hline $\begin{array}{l}\text { Difficult conversations and counselling } \\
\text { skills }\end{array}$ & $\begin{array}{l}\text { 'I don't feel particularly skilled and I find it especially difficult if you've been with - if you've known a family for } \\
\text { years... but then you realise that, Dad's actually... this is the beginning of his dying process... how do you have } \\
\text { that first conversation?' (GP02) } \\
\text { 'We're all expected to be counsellors, although none of us have had any counselling training, so if there were } \\
\text { some sort of people from the mental health team or counsellors that could come in and offer... sessions... } \\
\text { that would be useful.' (GPO3) }\end{array}$ \\
\hline Symptom management & $\begin{array}{l}\text { 'I know a drug chart, whenever I get one, I get really flustered because there are rules and criteria and different } \\
\text { things.' (GP09) } \\
\text { 'For me it is all the practical stuff that you guys mentioned, like drug doses and these whacking great doses of } \\
\text { morphine and is it saline or is it water or whatever.' (GP16) }\end{array}$ \\
\hline $\begin{array}{l}\text { Caring for patients with non-malignant } \\
\text { conditions }\end{array}$ & $\begin{array}{l}\text { 't is easier when they have got a terminal diagnosis like a cancer or something. When they have lots of } \\
\text { comorbidities and they are just starting to fail, that is really hard.' (GP13) }\end{array}$ \\
\hline Paediatric palliative care & $\begin{array}{l}\text { 'Paediatric terminal care, it's something that, thankfully, we don't see very much of and in fact are very ill } \\
\text { equipped to deal with I think... on the rare occasion that it does come, come along.' (GP03) }\end{array}$ \\
\hline
\end{tabular}

validity of simulated behavioural assessments as a way of evaluating communication skills, due to the ability to learn exam technique: GP 16: '[Simulations] probably wouldn't give you an accurate reflection of the course.' GP13: 'Actually, if we are getting into role play, you can learn how to tick the boxes quite easily.' [General sounds of agreement] GP13: 'We are masters at role play now.'

Self-assessment questionnaires to test the effects of education on confidence and knowledge were considered of limited use, but respondents reported answering honestly and felt they were acceptable if not too lengthy or burdensome: "We're notoriously bad at knowing how good or bad we're probably doing in a consultation. So... saying, 'Yes, I feel more confident now', or, 'I think that I'm better now' I don't think we're the best judges of the actual ultimate outcome" (GP17). Most GPs were in favour of patient and family feedback if done sensitively, ('asking them about their experience, what could be done better, what do they feel was missing' (GP24)) but some felt this inappropriate: "Saying to a relative or a patient, 'How do you think your doctor did in treating you as you're dying?' is the last thing they want to be thinking about, this filling in a questionnaire." (GP20). Timing patient and family outcome measurement sensitively was considered important, as was the way in which data are collected: 'If it's a familiar face doing that that would be okay, but I think if it came in the post it could be quite upsetting, or probably the return rate would be quite low.' (GP02). GPs were aware of possible confounders in measuring the effects of education on patient and family outcomes, e.g. 'People who return those [questionnaires] are going to be either really hacked off with you or really impressed.' (GP16).

\section{Discussion}

This study is one of the first to examine the needs and preferences of GPs and GP trainees regarding education in EoLC and how its effectiveness might be evaluated. Previous studies in the UK have explored education needs amongst GPs conducting out-of-hours care [17], but not amongst GPs with different levels of training and experience. This study identifies unmet educational needs in EoLC: participants reported that skills erode and remaining up to date is difficult, exposure during 
training is inadequate and inconsistent, and in clinical practice palliative care is complex and their confidence low. A key finding is that qualified GPs and trainee GPs valued mentoring, peer-support, and experiential learning alongside specialists in EoLC, over attending formal training. In terms of formal education, real case studies were valued more highly than didactic methods, and e-learning EoLC was not considered appropriate. Respondents emphasised that any formal education needed to be easily integrated into clinical practice and existing meetings. In terms of evaluation, participants felt $360^{\circ}$ appraisals were inaccurate, and questioned both the validity of assessments using simulated interactions and the acceptability of behavioural assessment using video. Selfassessment questionnaires and patient and family outcome measures were largely considered acceptable and potentially useful, if used and interpreted correctly.

Our findings support other studies in highlighting the limitations of current end of life care education for GPs and their lack of confidence in this area [9, 15-17], as well as educational needs relating to out-of-hours care [17], symptom control [20,41, 42], non-cancer diagnoses $[17,20,43]$, and counselling $[16,20]$. Where we add to the evidence is in identifying the need for practice-based mentorship and/or apprenticeship models in education in end of life care. We also describe specific educational needs around the identification and referral of patients for palliative care; roles, responsibilities and teamworking; local services and systems; and in paediatric palliative care. Of note, participants in general felt they had had sufficient communication skills training, despite still finding conversations about dying to be difficult. Perhaps what is needed is not more communication skills training, but qualitatively different communication skills training.

As in a study by Pype et al. in Belgium [21], we found that practical experience, including workplace learning through collaboration with palliative care specialists, was highly valued as a way to learn skills. Our participants were unanimously positive about collaborating with and learning from palliative care specialists. This suggests improvements in this area since 1998, when a study found that GPs questioned the extent to which they should defer to the specialist palliative care team [43]. Our finding that GPs had reservations about learning EoLC in an online format, preferring face-to-face education, contradicts other studies. A survey of GPs $(n=203$, $20.3 \%$ response rate) working for an independent provider of out-of-hours services in England found that e-learning was the preferred method $(67.5 \%, n=137)$ [17]. A randomised controlled trial in Spain [44, 45] also found that primary care physicians were satisfied with an online palliative care education programme. However, that programme integrated mentoring, which GPs in the current study also valued. E-learning in this area warrants further research.

A strength of this study is the diverse sample: clinicians ranging from junior trainees to experienced GPs, good representation from both genders, and participants of diverse ethnicities. However, as participants were recruited in a major city our findings might not be directly transferable to non-urban areas or other countries, where access to education and educational needs will differ [20]. GPs who participated in this study may also have had a particular interest in EoLC, and GPs with less interest may report different needs and experiences. In particular, GPs who did not attend due to lack of interest or time constraints may have even greater unmet and unknown needs. Finally, although we identified and discussed differences in the views of experienced GPs and GP trainees, the study was not designed to compare these groups in detail; this would be an interesting area for future research.

The clinical implications of the study include an identified need to improve GP education over several domains, primarily through implementing service models and interventions that provide access to experiential learning, mentorship and joint working with specialist palliative care providers. This may require a paradigm shift away from thinking of formal training as the best way to educate healthcare professionals, particularly in EoLC, which can be both personally difficult and clinically complex. Our findings suggest that formal education which is not supported and enhanced by real-life experience, resources and mentoring may be insufficient to bring about sustainable improvements in EoLC in primary care and a potential waste of resource. While this study was conducted in the UK, we suspect the need for experiential learning and mentorship in end of life care education is more widely applicable internationally. For example, we believe the standard education for physicians in the United States, the Education in Palliative and End-of-Life Care programme, does not currently use mentored real-life clinical situations to teach physicians in practice and in training how to provide EoLC. Further research is needed to adapt and evaluate service models and interventions to improve EoLC in primary care in local settings $[46,47]$ to identify best practice in GPs' education and support. In the UK, Macmillan GP facilitators funded since 2011 could play an important role in supporting primary care staff and enhancing education.

With the caveat that formal education must be implemented alongside systemic changes, this study also provides guidance for the formal education of GPs in EoLC. In the UK, the RCGP Palliative and End of Life Care Toolkit [48] to support GPs' provision of EoLC could be enhanced to include a more comprehensive, searchable database of training available to GPs and associated 
evidence. A current interdisciplinary course (Transforming EoLC) that is run for a variety of EoLC providers [30] incorporates some of the topics identified here. The course is highly evaluated and further research into its effectiveness warranted [30]. However, four topics are not covered in the generic course: identifying and referring patients for palliative care; out-of-hours care; caring for patients with non-malignant conditions; and paediatric palliative care. These topics may be of specific relevance in developing stand-alone education on EoLC for GPs. It is essential that any education rolled out for GPs is evidence-based and evaluated for effectiveness.

\section{Conclusions}

GPs require education and support in EoLC, particularly the management of complex clinical care and counselling. GPs value mentoring, peer-support, and experiential learning alongside EoLC specialists over formal training. Findings from this study can help inform EoLC educational and support interventions for GPs and guide the evaluation of such interventions.

\section{Abbreviations}

CCGs: Clinical Commissioning Groups; EoLC: End of Life Care; GP: General Practitioner; GSF: Gold Standards Framework; ST: Specialist Training

\section{Acknowledgements}

We thank all the GPs who participated, NHS Southwark Clinical Commissioning Group and local palliative care teams for facilitating recruitment, and Lara Klass for administrative assistance. We would also like to thank the journal's anonymous reviewers for their helpful comments.

\section{Funding}

This study was funded by Health Education South London. The funder had no role in study design; the collection, analysis and interpretation of data; the writing of the report; or the decision to submit the article for publication.

\section{Availability of data and materials}

The datasets analysed during the current study are available from the corresponding author on reasonable request.

\section{Authors' contributions \\ LS conceived of the study and obtained research funding together with $\mathrm{JK}$, $V R, S K, R G$, and RB. LS, JK, VR, SK, RG, and RB designed the study protocol. All authors contributed to drafting the focus group topic guide. LS and LB collected the data. LB drafted the first coding frame and revised it with guidance from $L S, J K, R G, S K$, and RB. LB applied the coding frame to all the data, JK and VR dual coded a sample of transcripts. LS led on writing the paper. All authors contributed to the paper and approved the final version for publication. All authors had full access to all of the data in the study and can take responsibility for the integrity of the data and the accuracy of the data analysis.}

\section{Competing interests}

The authors declare that they have no competing interests.

\section{Consent for publication}

Not applicable.

\section{Ethics approval and consent to participate}

Ethical approval was granted by King's College London Research Ethics Committee (BDM/14/15-11). Written informed consent was provided by all participants prior to data collection.

\section{Author details}

'University of Bristol, School of Social and Community Medicine, University of Bristol, 39 Whatley Road, Bristol BS8 2PS, UK. ${ }^{2}$ King's College London, Cicely Saunders Institute, Bessemer Road, Denmark Hill, London SE59PJ, UK. ${ }^{3}$ St Christopher's Hospice, 51-59 Lawrie Park Road, London SE26 6DZ, UK. ${ }^{4}$ Guy's \& St Thomas' NHS Foundation Trust, Great Maze Pond, London SE19RT, UK. ${ }^{5}$ King's College Hospital NHS Foundation Trust, Bessemer Road, Denmark Hill, London SE5 9RS, UK.

Received: 1 August 2016 Accepted: 17 February 2017

Published online: 09 March 2017

\section{References}

1. Mitchell GK, Reymond EJ, McGrath BP. Palliative care: promoting general practice participation. Med J Aust. 2004;180(5):207-8.

2. Murray SA, Boyd K, Sheikh A, Thomas K, Higginson IJ. Developing primary palliative care. BMJ. 2004;329(7474):1056-7.

3. Forrest S, Barclay S. Palliative care: a task for everyone. Br J Gen Pract. 2007;57(539):503.

4. Department of Health. End of Life Care Strategy - promoting high quality care for all adults at the end of life. London: UK Government; 2008. Available at https:/www.gov.uk/government/publications/end-oflife-carestrategy-promoting-high-quality-care-for-adults-at-the-end-of-their-life. Accessed 27 Feb 2017.

5. Thomas K, Paynton D. RCGP Commissioning Guidance in End of Life Care London: Royal College of General Practitioners. 2013. Available at www. rcgp.org.uk. Accessed 27 Feb 2017.

6. Gomes B, Calanzani N, Higginson I. Local preferences and place of death in regions within England 2010. London: Cicely Saunders International 2011. Available at http://www.kcl.ac.uk/lsm/research/divisions/cicelysaunders/ resources/key-reports/local-preferences-England.aspx. Accessed 27 Feb 2017.

7. Hunt KJ, Shlomo N, Addington-Hall J. End-of-life care and achieving preferences for place of death in England: results of a population-based survey using the VOICES-SF questionnaire. Palliat Med. 2014;28(5):412-21.

8. Burt J, Shipman C, Richardson A, Ream E, Addington-Hall J. The experiences of older adults in the community dying from cancer and non-cancer causes: a national survey of bereaved relatives. Age Ageing. 2010;39(1):86-91.

9. Mitchell GK. How well do general practitioners deliver palliative care? A systematic review. Palliat Med. 2002;16(6):457-64.

10. Parliamentary and Health Service Ombudsman. Dying Without Dignity: Investigations by the Parliamentary and Health Service Ombudsman into complaints about end of life care. London: Parliamentary and Health Service Ombudsman 2015. Available at https://www.ombudsman.org.uk/ publications/dying-without-dignity-0. Accessed 27 Feb 2017.

11. Gott M, Seymour J, Ingleton C, Gardiner C, Bellamy G. 'That's part of everybody's job': the perspectives of health care staff in England and New Zealand on the meaning and remit of palliative care. Palliat Med. 2012;26(3):232-41.

12. Pivodic L, Harding R, Calanzani N, McCrone P, Hall S, Deliens L, Higginson IJ, Gomes B. Home care by general practitioners for cancer patients in the last 3 months of life: An epidemiological study of quality and associated factors. Palliative Medicine. 2016;30(1):64-74. doi:10.1177/0269216315589213.

13. Addicott R. End of Life Care: An Inquiry into the Quality of General Practice in England. London: The King's Fund 2010. Available at https://www. kingsfund.org.uk/sites/files/kf/field/field_document/end-of-lifecare-gpinquiry-research-paper-mar11.pdf. Accessed 27 Feb 2017.

14. Lloyd-Williams M, Carter YH. General practice vocational training in the UK: what teaching is given in palliative care? Palliat Med. 2003;17(7):616-20

15. Shipman C, Gysels M, White P, Worth A, Murray SA, Barclay S, Forrest S, Shepherd J, Dale J, Dewar S, et al. Improving generalist end of life care: national consultation with practitioners, commissioners, academics, and service user groups. BMJ 2008;337:a1720.

16. Low J, Cloherty M, Wilkinson S, Barclay S, Hibble A. A UK-wide postal survey to evaluate palliative care education amongst General Practice Registrars. Palliat Med. 2006;20(4):463-9.

17. Magee C, Koffman J. Out-of-hours palliative care: what are the educational needs and preferences of general practitioners? BMJ Support Palliat Care. 2015.

18. House of Commons Health Committee. End of Life Care: Fifth Report of Session 2014-15. London: The Stationery Office Limited 2015. Available at 
https://www.publications.parliament.uk/pa/cm201415/cmselect/cmhealth/ 805/805.pdf. Accessed 27 Feb 2017.

19. Alvarez MP, Agra Y. Systematic review of educational interventions in palliative care for primary care physicians. Palliat Med. 2006;20(7):673-83.

20. Shipman C, Addington-Hall J, Barclay S, Briggs J, Cox I, Daniels L, Millar D. Educational opportunities in palliative care: what do general practitioners want? Palliat Med. 2001;15(3):191-6.

21. Pype P, Symons L, Wens J, Van den Eynden B, Stes A, Deveugele M. Health care professionals' perceptions towards lifelong learning in palliative care for general practitioners: a focus group study. BMC Fam Pract. 2014;15(1):36.

22. Revill S. GP Pilot Project Evaluation. 2011.

23. Thomas K, Armstrong-Wilson J. ACPEL Abstract: 'Going for gold': Achieving top quality end of life care in GP practices and mainstreaming Advance Care Planning (ACP) discussions: findings from the first GP practices to be GSF accredited. BMJ Support Palliat Care. 2013;3(2):244.

24. Dale J, Petrova M, Munday D, Koistinen-Harris J, Lall R, Thomas K. A national facilitation project to improve primary palliative care: impact of the Gold Standards Framework on process and self-ratings of quality. Qual Saf Health Care. 2009;18(3):174-80.

25. Slort W, Blankenstein AH, Schweitzer BP, Knol DL, van der Horst HE, Aaronson NK, Deliens L. Effectiveness of the palliative care 'Availability, Current issues and Anticipation' (ACA) communication training programme for general practitioners on patient outcomes: a controlled trial. Palliat Med. 2014;28(8):1036-45.

26. Slort W, Blankenstein AH, Schweitzer BP, Knol DL, Deliens L, Aaronson NK, van der Horst HE. Effectiveness of the ACA (Availability, Current issues and Anticipation) training programme on GP-patient communication in palliative care; a controlled trial. BMC Fam Pract. 2013;14:93.

27. Kristie Saumure LMG. Data Saturation. In: The SAGE Encyclopedia of Qualitative Research Methods. Thousand Oaks: SAGE Publications, Inc; 2008. p. 196-7.

28. Morgan DL. Focus Groups as Qualitative Research. California: Sage Publications; 1997

29. WHO definition of palliative care [http://www.who.int/cancer/palliative/ definition/en/]. Accessed 27 Feb 2017.

30. Selman L, Robinson V, Klass L, Khan S, George R, Shepherd K, Burman R, Koffman J. Improving confidence and competence of healthcare professionals in end-of-life care: an evaluation of the Transforming End of Life Care' course at an acute hospital trust. BMJ Support Palliat Care. 2016:6:231-36. http://dx.doi.org/10.1136/bmjspcare-2015-000879.

31. Seale C. The quality of qualitative research. London: Sage; 1999.

32. Braun V, Clarke V. Using thematic analysis in psychology. Qual Res Psychol. 2006;3(2):77-101.

33. Armstrong D, Gosling A, Weinman J, Marteau T. The place of inter-rater reliability in qualitative research: an empirical study. Sociology. 1997;31(3):597-606.

34. Mays N, Pope C. Assessing quality in qualitative research. BMJ. 2000:320:50-2.

35. NVivo qualitative data analysis Software; QSR International Pty Ltd. Version 10, 2012.

36. The Amber Care Bundle [http://www.ambercarebundle.org/forprofessionals/ for-professionals.aspx]. Accessed 27 Feb 2017.

37. Carey I, Shouls S, Bristowe K, Morris M, Briant L, Robinson C, Caulkin R, Griffiths M, Clark K, Koffman J, et al. Improving care for patients whose recovery is uncertain. The AMBER care bundle: design and implementation. BMJ Support Palliat Care. 2015;5(1):12-8.

38. National Gold Standards Framework Centre for End of Life Care 2017. www.goldstandardsframework.org.uk. Accessed 27 Feb 2017.

39. Coordinate My Care [http://coordinatemycare.co.uk/. Accessed 27 Feb 2017.

40. DDepartment of Health: Fast Track Pathway Tool for NHS Continuing Healthcare: November 2012 (Revised). In. Accessed 1 Aug. 2016 https:// www.gov.uk/government/publications/national-framework-fornhscontinuing-healthcare-and-nhs-funded-nursing-care; 2012.

41. Hanratty B. Palliative care provided by GPs: the carer's viewpoint. Br J Gen Pract. 2000;50(457):653-4.

42. Grande GE, Barclay SI, Todd CJ. Difficulty of symptom control and general practitioners'knowledge of patients' symptoms. Palliat Med. 1997;11(5):399-406.

43. Field D. Special not different: general practitioners' accounts of their care of dying people. Soc Sci Med. 1998;46(9):1111-20.
44. Pelayo M, Cebrian D, Areosa A, Agra Y, Izquierdo J, Buendia F. Effects of online palliative care training on knowledge, attitude and satisfaction of primary care physicians. BMC Fam Pract. 2011;12(1):37.

45. Pelayo-Alvarez M, Perez-Hoyos S, Agra-Varela Y. Clinical Effectiveness of Online Training in Palliative Care of Primary Care Physicians. J Palliat Med. 2013;16(10):1188-96

46. Marshall D, Howell D, Brazil K, Howard M, Taniguchi A. Enhancing family physician capacity to deliver quality palliative home care: an end-of-life, shared-care model. Can Fam Physician. 2008:54(12):1703-e1707.

47. McKinlay E, McBain L. Evaluation of the Palliative Care Partnership: a New Zealand solution to the provision of integrated palliative care. N Z Med J. 2007;120(1263):U2745.

48. Palliative and End of Life Care Toolkit [http://www.rcgp.org.uk/clinical-andresearch/toolkits/palliative-and-endof-life-care-toolkitaspx]. Accessed 27 Feb 2017.

\section{Submit your next manuscript to BioMed Central and we will help you at every step:}

- We accept pre-submission inquiries

- Our selector tool helps you to find the most relevant journal

- We provide round the clock customer support

- Convenient online submission

- Thorough peer review

- Inclusion in PubMed and all major indexing services

- Maximum visibility for your research

Submit your manuscript at www.biomedcentral.com/submit
Biomed Central 